\title{
MARATHON PERFORMANCE IN RELATION TO MAXIMAL AEROBIC POWER AND TRAINING INDICES IN FEMALE DISTANCE RUNNERS
}

\author{
R. D. HAGAN, PhD*, S. J. UPTON, PhD, J. J. DUNCAN, MS and L. R. GETTMAN, PhD \\ *Public Health and Preventive Medicine, Texas College of Osteopathic Medicine and \\ Institute for Aerobics Research, Dallas, Texas
}

\begin{abstract}
The purpose of this study was to examine the relationships of marathon performance time (MPT) to maximal aerobic power $\left(\mathrm{VO}_{2} \mathrm{max}\right)$, physical characteristics, and training indices recorded for 12 weeks prior to a race in 35 female distance runners. The marathon experience of the subjects ranged from two to fifteen races. Physical and aerobic power characteristics $(\bar{x} \pm$ S.D.) were: age, $35.7 \pm 8.5 \mathrm{yr}$; height, $166.4 \pm 5.7 \mathrm{~cm}$; weight, $55.1 \pm 5.7 \mathrm{~kg}$; body fat, $15.7 \pm 5.0 \%$; $\mathrm{VO}, \mathrm{max}, 56.5 \pm$ $6.2 \mathrm{ml} . \mathrm{kg}^{-1} \cdot \mathrm{min}^{-1}$. Marathon time for this race averaged $227.0 \pm 31.6 \mathrm{~min}$. Records from individual training diaries indicated the runners averaged $71.0 \pm 10.0$ workout days, $10.0 \pm 10.0$ two day-1 workouts, $81.0 \pm 8.0$ total workouts, $12.3 \pm 1.8 \bar{x}$ km.workout ${ }^{-1}, 5402.8 \pm 1302.6$ total training $\min , 187.0 \pm 18.0 \mathrm{~m} . \mathrm{min}^{-1}$ training pace, $112.2 \pm 32.1 \mathrm{max} \mathrm{km} . \mathrm{wk}^{-1}, 83.1 \pm 23.4$ $\bar{x} \mathrm{~km} . w^{-1}, 998.8 \pm 282.6 \mathrm{~km} .12 \mathrm{wk}^{-1}$ and $13.8 \pm 2.4 \bar{x} \mathrm{~km}$.day ${ }^{-1}$. MPT was positively correlated to body $\operatorname{mass}$ index $(r=0.52)$, and body fat $(r=0.52)$ but negatively related to $\mathrm{VO}_{2} \max (r=-0.65)$. MPT was also negatively related to previous marathons

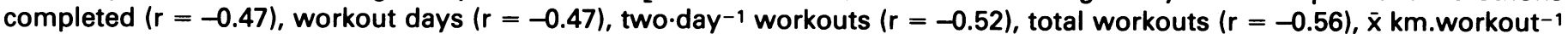
$(r=-0.58)$, total training $\min (r=-0.56), m \cdot m i n-1$, training pace $(r=-0.66)$, max km.wk-1 $(r=-0.70), \bar{x} k m . w k-1(r=-0.74)$, km.12 $w^{-1}(r=-0.74)$, and $\bar{x} k m . d a y^{-1}(r=-0.77)$. MPT for our population of runners may be predicted $\left(r=0.82, R^{2}=0.68\right)$ by the following equation:

MPT, $(\min )=449.88-7.61\left(\bar{x} \mathrm{~km}^{2} \cdot \mathrm{day}^{-1} \mathrm{run}\right)-0.63\left(\mathrm{~m} \cdot \mathrm{min}{ }^{-1}\right.$, training pace $)$; SEE $= \pm 18.4 \mathrm{~min}$.
\end{abstract}

Key words: Marathon performance time, $\mathrm{VO}_{2}$ max, training indices, Women

\section{INTRODUCTION}

Several studies (Foster et al, 1977; Farrell et al, 1979; Davies and Thompson, 1979; Maughan and Leiper, 1983) have reported that maximum aerobic power $\left(\mathrm{VO}_{2} \max \right)$ is highly correlated to marathon performance time (MPT), while other studies (Davies and Thompson, 1979; Sjödin and Svedenhag, 1985) have suggested that the \% of $\mathrm{VO}_{2} \max$ utilised during the run is also important to MPT. Foster (1983) has reported that $\mathrm{VO}_{2}$ max is the most important factor in predicting MPT and that training volume is of relatively minor importance in the prediction of marathon success. However, these findings are in contrast to the work of Hagan et al (1981) and Slovic (1977) who found that factors such as age, number of previous marathons, performance times for distances up to 10 miles, and numerous indices of training were, also, highly predictive of MPT.

While female runners generally have lower body weight and lower $\mathrm{VO}_{2}$ max compared with male runners (Pate and Kriska, 1984; Wilmore and Brown, 1974), it is known that women can have performance times equivalent to and in some cases, superior to those of men (Pate and Kriska, 1984; Wells et al, 1981). Wells et al (1981) have suggested that training volume and pace, as well as training strategies, are more important to the MPT of female runners than is their $\mathrm{VO}_{2}$ max level or $\% \mathrm{VO}_{2}$ max utilised during the race.

Address for correspondence:

R. Donald Hagan, PhD

Director of Research

Division of Health and Human Fitness

Public Health and Preventive Medicine

Texas College of Osteopathic Medicine

Camp Bowie at Montgomery

Fort Worth, TX 76107
Except for the nine women studied by Davies and Thompson (1979) and the ten women evaluated by Maughan and Leiper (1983), all previous investigations examining factors predictive of MPT have concentrated on male runners. Therefore, the purpose of this study was to examine the relationship of MPT to maximal aerobic power, physical characteristics, and training indices in female distance runners.

\section{METHODS AND PROCEDURES}

Thirty-five female runners, age $19-54$ years, participated as subjects in this investigation (Table I). The nature and purpose of the study and risks involved were explained and written consent was obtained from each participant. All subjects had run at least one previous marathon. Eight of the runners had completed two previous marathons, 14 had completed between three and eight marathons, while two had previously finished 14 and 15 races, respectively. Runners completing less than three marathons were considered as novice marathoners $(n=19$ ), while those runners who had completed 3 or more races were considered as experienced marathoners $(n=16)$. This designation is equivalent to that used in our previous investigation (Hagan et al, 1981), and to that of Franklin et al (1978).

Marathon performance times were recorded for the 1980 White Rock Marathon, Dallas, Texas. During the race the ambient temperature and relative humidity (RH) ranged from $18.3^{\circ}$ to $20.0^{\circ} \mathrm{C}$ and $87 \%$ to $97 \% \mathrm{RH}$, respectively. During twelve consecutive weeks prior to the race, each subject completed a medical history questionnaire and maintained a comprehensive training diary, which consisted of the number of daily workouts, and distance, duration, and pace of each run. Training diaries were collected after the race and tabulated for a 12 week training period prior to the race. Tests to assess maximal height, 
TABLE I

Physical characteristics of subjects. Mean \pm SD

\begin{tabular}{|c|c|c|c|}
\hline \multirow[b]{2}{*}{ Variable } & \multicolumn{3}{|c|}{ Group } \\
\hline & $\begin{array}{l}\text { Novice } \\
(n=19)\end{array}$ & $\begin{array}{l}\text { Experienced } \\
\quad(n=16)\end{array}$ & $\begin{array}{c}\text { Combined } \\
(n=35)\end{array}$ \\
\hline Age (yr) & $37.2 \pm 9.2$ & $34.1 \pm 7.5$ & $35.7 \pm 8.5$ \\
\hline Height (cm) & $167.0 \pm 6.6$ & $165.7 \pm 4.5$ & $166.4 \pm 5.7$ \\
\hline Weight (kg) & $56.5 \pm 5.7$ & $53.4 \pm 5.4$ & $55.1 \pm 5.7$ \\
\hline Body Mass Index $(\mathrm{Wt} / \mathrm{Ht})$ & $0.34 \pm 0.03$ & $0.32 \pm 0.03$ & $0.33 \pm 0.03$ \\
\hline Body Fat $(\%)$ & $16.4 \pm 5.8$ & $14.8 \pm 8.0$ & $15.7 \pm 5.0$ \\
\hline 乏 7 Skinfolds (mm) & $75.5 \pm 20.7$ & $71.6 \pm 16.4$ & $73.7 \pm 18.7$ \\
\hline $\mathrm{VO}_{2} \max \left(\mathrm{ml} \cdot \mathrm{kg}^{-1} \cdot \mathrm{min}^{-1}\right)$ & $54.7 \pm 6.0$ & $58.7 \pm 5.9$ & $56.5 \pm 6.2$ \\
\hline Marathon performance time (min) & $242.3 \pm 29.8$ & $208.9 \pm 23.7$ & $227.0 \pm 31.6$ \\
\hline
\end{tabular}

weight, body fat, sum of 7 skinfolds and the maximum aerobic power of each subject were conducted on each subject within 8 weeks prior to the marathon race.

For each subject, height was recorded to the nearest $0.1 \mathrm{~cm}$ using a GPM anthropometer, and weight was recorded to the nearest $10 \mathrm{~g}$. Body mass index (BMI) was calculated as weight/height (kg.cm-1) (Florey, 1970). Florey (1970) has reported that this expression of BMI is the best ratio for women of different sizes. Skinfold measurements were taken anatomically on the right side at the chest, axilla, triceps, subscapula, abdomen, suprailium and thigh (Jackson et al, 1980). All measurements were obtained using a Lange skinfold caliper with a constant pressure of 10 g. $\mathrm{mm}^{-2}$. Body density was determined by hydrostatic weighing, and body fat was calculated according to the equation of Siri et al (1961).

Each subject performed an incremental-load treadmill test to voluntary exhaustion using the Bruce protocol (Doan et al, 1965). Vigorous verbal motivation was given during the test. Oxygen uptake was measured continuously during exercise by the open-circuit method (Hagan et al, 1980). The peak oxygen uptake for one minute during the test was taken as $\mathrm{VO}_{2}$ max. Ventilatory volumes were obtained from inspired air by using a Parkinson-Cowan dry gasmeter. Expired oxygen and carbon dioxide percentages were determined from mixed air by Applied Electrochemistry S-3A and Beckman LB-2 gas analysers, respectively.

During the treadmill test, each subject's cardiac response was continuously monitored by a 12-lead electrocardiagram. Heart rate was recorded during the last 15 seconds of each minute with a full 12-lead recording at the end of each stage of the test. Blood pressure was monitored at the end of each walking stage using a sphygmomanometer and pressure cuff.

The relation between MPT and other selected measures were analysed utilising bivariate correlation analysis. Multiple regression analysis was used to develope multiple regression equations predicting MPT for novice and experienced runners, and all runners combined. This analysis was performed by a step-forward, stepwise multiple regression analysis procedure. An alpha level of 0.05 was used to indicate significance.

\section{RESULTS}

Group values for the various training indices for novice and experienced marathoners and for all runners combined are presented in Table II. Correlation coefficients $(r)$ and coefficients of determination $\left(r^{2}\right)$ relating marathon performance time to selected physical characteristics and training indices are presented in Tables III and IV. When all marathon runners were considered together, marathon performance time was positively related to body weight, body mass index, per cent body fat, and sum 7 skinfolds, negatively related to maximal aerobic power and all training indices. In the novice runners, the physical characteristics of $\mathrm{VO}_{2}$ max and the sum of 7 skinfolds gave the best correlation to MPT, while in the experienced runners the best correlations were found for BMI, body weight, per cent body fat, and $\mathrm{VO}_{2}$ max. In the novice runners, the training indices of mean distance run per day $\left(\bar{X} \mathrm{~km} \mathrm{day}^{-1}\right)$, mean training pace, total training distance $(\mathrm{km})$ run, and mean distance run per week ( $\bar{X}$ km.wk-1) gave the best correlation to MPT. In the experienced runners, mean workout pace, mean $\mathrm{km} \mathrm{wk}^{-1}$, mean $\mathrm{km}$.day-1, total training $\mathrm{km}$ run, and total workout days were the best correlates of MPT.

TABLE II

Training indices for 12 weeks prior to the marathon. Mean \pm SD

\begin{tabular}{|c|c|c|c|}
\hline \multirow[b]{2}{*}{ Variable } & \multicolumn{3}{|c|}{ Group } \\
\hline & $\begin{array}{l}\text { Novice } \\
(n=19)\end{array}$ & $\begin{array}{l}\text { Experienced } \\
\quad(n=16)\end{array}$ & $\begin{array}{c}\text { Combined } \\
(n=35)\end{array}$ \\
\hline Previous Marathons (\#) & $1.4 \pm 0.5$ & $5.6 \pm 3.7$ & $3.3 \pm 3.3$ \\
\hline $\bar{X}$ km.workout ${ }^{-1}$ & $11.6 \pm 1.7$ & $13.1 \pm 1.7$ & $12.3 \pm 1.8$ \\
\hline $\bar{X}$ km.day $^{-1}$ & $12.6 \pm 2.0$ & $15.3 \pm 2.0$ & $13.8 \pm 2.4$ \\
\hline $\bar{X} \mathbf{k m} \cdot \mathbf{w k}^{-1}$ & $70.4 \pm 19.2$ & $98.1 \pm 19.0$ & $83.1 \pm 23.4$ \\
\hline Max km.wk-1 & $96.9 \pm 22.2$ & $130.2 \pm 33.2$ & $112.2 \pm 32.1$ \\
\hline $\bar{X}$ training pace $\left(\mathrm{m} \cdot \mathrm{min}^{-1}\right)$ & $182.3 \pm 14.6$ & $192.3 \pm 20.2$ & $187.0 \pm 18.0$ \\
\hline Total workout km run $12 w^{-1}$ & $845.8 \pm 230.0$ & $1180.6 \pm 222.94$ & $998.8 \pm 282.6$ \\
\hline Total workout days & $66.0 \pm 9.0$ & $76.0 \pm 6.0$ & $71.0 \pm 10.0$ \\
\hline Two day ${ }^{-1}$ workouts (\#) & $6.0 \pm 9.0$ & $14.0 \pm 10.0$ & $10.0 \pm 10.0$ \\
\hline Total workouts & $73.0 \pm 16.0$ & $90.0 \pm 15.0$ & $81.0 \pm 18.0$ \\
\hline
\end{tabular}

TABLE III

Relationship of marathon performance time to selected physical characteristicst

\begin{tabular}{|c|c|c|c|c|c|c|}
\hline \multirow[b]{3}{*}{ Variable } & \multicolumn{6}{|c|}{ Group } \\
\hline & \multicolumn{2}{|c|}{$\begin{array}{l}\text { Novice } \\
(n=19)\end{array}$} & \multicolumn{2}{|c|}{$\begin{array}{l}\text { Experienced } \\
\quad(n=16)\end{array}$} & \multicolumn{2}{|c|}{$\begin{array}{c}\text { Combined } \\
(n=35)\end{array}$} \\
\hline & $r$ & $r^{2}$ & $r$ & $r^{2}$ & $\mathbf{r}$ & $r^{2}$ \\
\hline Age (yr) & 0.14 & 0.02 & 0.30 & 0.09 & 0.26 & 0.07 \\
\hline Height (cm) & -0.03 & 0.00 & 0.45 & 0.20 & 0.16 & 0.02 \\
\hline Weight (kg) & 0.26 & 0.07 & 0.69 & 0.48 & 0.49 & 0.24 \\
\hline BMI (wt/ht) & 0.31 & 0.10 & 0.70 & 0.49 & $0.52^{*}$ & 0.27 \\
\hline Body Fat (\%) & $0.47^{*}$ & 0.22 & $0.67^{*}$ & 0.45 & $0.52^{*}$ & 0.27 \\
\hline Sum Skinfolds (mm) & $0.51^{*}$ & 0.26 & $0.58^{*}$ & 0.34 & $0.51 *$ & 0.26 \\
\hline $\mathrm{VO}_{2} \max \left(\mathrm{ml} \cdot \mathrm{kg}^{-1} \cdot \mathrm{min}^{-1}\right)$ & $-0.60 *$ & 0.36 & $-0.60^{*}$ & 0.36 & $-0.65^{*}$ & 0.42 \\
\hline
\end{tabular}

† r values represent Pearson product-moment coefficients.

* $p<0.001$ to $p<0.022$

Multiple regression equations for predicting marathon performance time for novice, experienced and all runners combined are presented in Table V. Step-wise regression analysis indicated that for all runners combined $68 \%$ of the marathon performance time could be accounted for by an equation which included training pace and average training kilometres per day. In novice runners, who had completed 


\section{TABLE IV}

Relationship of marathon performance time to selected training indicest

\begin{tabular}{|c|c|c|c|c|c|c|}
\hline \multirow[b]{3}{*}{ Variable } & \multicolumn{6}{|c|}{ Group } \\
\hline & \multicolumn{2}{|c|}{$\begin{array}{c}\text { Novice } \\
(n=19)\end{array}$} & \multicolumn{2}{|c|}{$\begin{array}{c}\text { Experienced } \\
(n=16)\end{array}$} & \multicolumn{2}{|c|}{$\begin{array}{c}\text { Combined } \\
(n=35)\end{array}$} \\
\hline & $\mathbf{r}$ & $\mathbf{r}^{2}$ & $r$ & $r^{2}$ & $\mathbf{r}$ & $r^{2}$ \\
\hline Total Workout days & -0.08 & 0.01 & $-0.64^{*}$ & 0.41 & $-0.47^{*}$ & 0.22 \\
\hline Prev. Marathons & -0.30 & 0.09 & -0.27 & 0.7 & -0.47 & 0.22 \\
\hline Total Workouts & -0.31 & 0.10 & $-0.57^{*}$ & 0.32 & $-0.56^{*}$ & 0.31 \\
\hline Total_Training Min. & -0.34 & 0.12 & $-0.46 t$ & 0.21 & $-0.56^{*}$ & 0.31 \\
\hline Two day-1 Workouts & $-0.43 t$ & 0.18 & $-0.43 t$ & 0.18 & $-0.52^{*}$ & 0.27 \\
\hline $\bar{X}$ km.workout ${ }^{-1}$ & $-0.50 t$ & 0.25 & $-0.42 t$ & 0.18 & $-0.58 *$ & 0.34 \\
\hline $\bar{X} k m \cdot w k^{-1}$ & $-0.54^{*}$ & 0.29 & $-0.76^{*}$ & 0.58 & $-0.74^{*}$ & 0.55 \\
\hline $\begin{array}{r}\text { Total training } \\
\text { km.12 } w^{-1}\end{array}$ & $-0.54^{*}$ & 0.29 & $-0.76^{*}$ & 0.58 & $-0.74^{*}$ & 0.55 \\
\hline Max km.wk-1 & $-0.57^{*}$ & 0.32 & $-0.67^{*}$ & 0.45 & $-0.70 *$ & 0.49 \\
\hline $\bar{X} \mathrm{~m} \cdot \mathrm{min}^{-1}$ training pace & $-0.54^{*}$ & 0.29 & $-0.78 *$ & 0.61 & $-0.66^{*}$ & 0.44 \\
\hline $\bar{X}$ km.day $^{-1}$ & $-0.69^{*}$ & 0.48 & $-0.65^{*}$ & 0.42 & $-0.77^{*}$ & 0.59 \\
\hline
\end{tabular}

t $\mathrm{r}$ values represent Pearson product-moment coefficients

${ }^{*} p<0.001,+p<0.05$

fewer than three previous marathons ( $n=19$ ), $48 \%$ of the marathon performance time could be attributed to average training distance per day. For the experienced runners, who had completed three or more previous marathons, $76 \%$ of the variation in marathon performance time could be related to body mass index and training pace.

\section{DISCUSSION}

Female marathon runners have been reported to have a $\mathrm{VO}_{2}$ max between 53.5 and $68.8 \mathrm{ml}^{\mathrm{kg}} \mathrm{kg}^{-1} \cdot \mathrm{min}^{-1}$, a body mass between 50.4 and $57.2 \mathrm{~kg}$, and a body fat between $11.4 \%$ and 15.2\% (Davies and Thompson, 1979; Jordan, 1977; Wells et al, 1981; Wilmore and Brown, 1974). Our women runners fell within these ranges, and thus, are similar in physical characteristics to other female marathoners.

In men, several studies have shown that maximal aerobic power is the best predictor of MPT, while other studies have found $\mathrm{VO}_{2}$ max to be of lesser importance to MPT than other variables. Foster (1983), Farrell et al (1979), Foster et al (1977), and Maughan and Leiper (1983) reported that MPT was highly related to $\mathrm{VO}_{2} \max (r=-0.96$, $r=-0.91, r=0.88$, and $r \equiv-0.86$, respectively), while Davies and Thompson (1979) and Sjödin and Svedenhag (1985) reported lower correlations $(r=-0.82$ and $r=-0.78$, respectively). However, Hagan et al (1981) found an even lower correlation coefficient between MPT and $\mathrm{VO}_{2} \max$ of $r=-0.63$.

In women, Davies and Thompson (1979) and Maughan and Leiper (1983) reported correlation coefficients of $r=-0.43$ and $r=-0.63$, respectively, between $\mathrm{VO}_{2}$ max and MPT. For our women runners, the correlation coefficient between $\mathrm{VO}_{2}$ max and MPT was $r=-0.65$, which is similar to that reported by Maughan and Leiper (1983) for women. The moderate correlation coefficient found for our women runners is probably due to the large number of subjects studied, their heterogeneous physical and training characteristics, environmental conditions during the race and the wide range of marathon performance times recorded during the race. Thus, our finding suggests that $\mathrm{VO}_{2}$ max is of moderate importance to marathon performance in women distance runners.

Physical characteristics such as body mass, BMI, body fat and the sum of seven skinfolds also appear to be related to MPT. Maughan and Leiper (1983) found in male and female runners correlation coefficients of 0.68 and 0.78 , respectively, between MPT and body fat. In our previous study of male runners (Hagan et al, 1981) we reported correlation coefficients of $r=0.41$ and $r=0.43$ for MPT and body mass and 7 skinfolds, respectively. These values are slightly lower, but are comparable to our values for women runners of $r=0.51$ and $r=0.49$ for MPT and body weight and seven skinfolds, respectively. Interestingly, in our women, BMI was a better predictor of MPT with a correlation $r=\mathbf{0 . 5 2}$ for all runners combined and $r=0.70$ for the experienced runners. These findings support the observations of Pugh (1971) that a larger body size increases the air resistance to running which in turn increases or prolongs performance time, while a smaller, leaner runner will have a lower air resistance during running and a faster marathon performance time.

Previous investigations in men (Foster, 1983; Foster and Daniels, 1975; Franklin et al, 1978; Grant et al, 1984; Hagan et al, 1981; Slovic, 1977) and women (Wells et al, 1981) suggest that factors such as training frequency, distance run and running pace are important contributors to MPT. Foster (1983) reported a correlation coefficient between distance run per week and MPT of $r=-0.61$. Grant et al (1984) reported a correlation coefficient of -0.38 between MPT and training distance per week, while Franklin et al (1978) reported correlation coefficients of $-0.41,-0.53$, and

TABLE V

Regression equations for novice, experienced, and combined marathoners

\begin{tabular}{lccccc}
\hline & $\begin{array}{c}\text { Previous } \\
\text { marathon }\end{array}$ & Equation & SEE* $^{*}$ & $R$ & $R^{2}$ \\
\hline $\begin{array}{l}\text { Novice } \\
(n=19)\end{array}$ & $<3$ & MPT $(\min )=369.58-10.1\left(X_{1}\right)$ & $\pm 22.2 \mathrm{~min}$ & 0.69 & 0.48 \\
$\begin{array}{l}\text { Experienced } \\
(n=16)\end{array}$ & $>3$ & MPT $(\min )=214.24+393.07\left(X_{2}\right)$ & $\pm 12.4 \mathrm{~min}$ & 0.87 & 0.76 \\
$\begin{array}{l}\text { Combined } \\
(n=35)\end{array}$ & & MPT $\left(\min =449.88-7.61\left(X_{1}\right)\right.$ & $\pm 18.4 \mathrm{~min}$ & 0.82 & 0.68 \\
& & $-0.63\left(X_{3}\right)$ & & & \\
\hline
\end{tabular}

* SEE = standard error of the estimate

$X_{1}=\bar{X}$ km.day ${ }^{-1}$ run; $X_{2}=B M I ; X_{3}=$ training pace (m.min $\left.{ }^{-1}\right)$ 
-0.31 for first-time, second-time, and experienced marathoners, respectively. In .our previous study of male runners (Hagan et al, 1981) we found correlation coefficients of $r=-0.67$ between MPT and both mean distance run per week and total workout distance run. In our present study of female runners, we found a correlation coefficient of $r=-0.74$ between MPT and total workout distance run and mean distance run per week, respectively, and a correlation coefficient of $r=-0.68$ between MPT and training pace. Thus, our findings support the observation of Wells et al (1981) that training volume and pace may be more important predictors of marathon performance in women runners than their $\mathrm{VO}_{2}$ max.

Several previous investigations have developed multiple regression equations utilising a variety of factors to predict MPT for male distance runners. Foster and Daniels (1975) and Slovic (1977) developed equations that incorporated such factors as one-, five- and ten-mile performance time, estimated $\mathrm{VO}_{2}$ max, number of previous marathons completed, single longest training run, and total distance run for $\mathbf{8}$ weeks prior to the race. In our previous study (Hagan et al, 1981) we found that age, measured $\mathrm{VO}_{2}$ max, mean workout pace and distance, total workout days, total number of workouts, and total workout distance gave the best prediction of MPT.

In our current study, we developed equations for the experienced and novice runners, and for all runners combined as we did in our previous study of men (Hagan et al, 1981). In the novice runners, distance run per day was the sole factor predicting MPT, while in the experienced runner, BMI and workout pace became the best predictive factors. Interestingly, when the groups were combined, distance run per day and workout pace became the most powerful predictors of MPT. This is similar to the findings from the bivariate analysis, and thus, may be the reason $\mathrm{VO}_{2}$ max was excluded as a contributing factor to MPT.

Compared with the studies involving men, our study indicates that in female runners, MPT can be predicted utilising a fewer number of independent variables. In men, Foster (1983) and Slovic (1977) found that 3, and 3 to 5 variables, respectively, were important for MPT, while in our previous study (Hagan et al, 1981) we found that 4 variables for experienced runners and 5 variables for novice and experienced combined produced the best equations. This may have been due to the different durations of time over which the training measures were accumulated. The training volume data used in the equations developed by Foster (1983) and Foster and Daniels (1975) and Slovic (1977), were for 8 week periods of training, while the equations developed in our previous study (Hagan et al, 1981) were from training records accumulated over a 9 week period. This would suggest that the accumulation of training information over an extended period of time might reduce the number of factors predicting MPT. In order to answer this question we entered into the stepwise regression procedure the total distance run for both 8 and 9 weeks prior to the marathon to see if these measures might yield prediction equation similar to these of Slovic (1977) and to Hagan et al (1981). However, our analysis revealed that regardless of the total distance run 8,9 or 12 weeks prior to the marathon the equation variables remained unchanged. Thus, our findings suggest that in women marathoners one or two variables can be used to predict MPT.
The various multiple regression equations developed to predict MPT vary in their predictive capacity. Davies and Thompson (1979) reported an $\mathbf{R}^{2}$ value of 0.99 when $\mathrm{VO}_{2}$ $\max$ and $\% \mathrm{VO}_{2}$ max utilised during the run were used to predict MPT. However, it is not surprising that $\% \mathrm{VO}_{2} \max$ utilised during the run would readily be predictive of the actual MPT. Foster (1983) found that $\mathrm{VO}_{2} \max$ alone predicted MPT with an $R^{2}$ value of 0.91. Foster's (1983) findings are difficult to explain in light of our initial study (Hagan et al, 1981) of men in which $\mathrm{VO}_{2}$ max was only one of several factors to predict MPT.

The findings from male marathoners as reported by Slovic (1977) and from our previous study (Hagan et al 1981) are similar to those found in the present investigation. Slovic's (1977) equations that included an individual's fastest time for the one, five, and ten-mile distance yielded $R^{2}$ values 0.52 and 0.55 . Our equations yielded $R^{2}$ values ranging from 0.48 to 0.76 . Interestingly, our equation for all

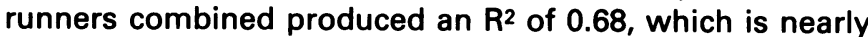
equivalent to the $R^{2}$ of 0.71 reported for male runners from our previous study.

In conclusion, it appears that for the novice runner, establishing a training base is more important in the early development of the marathon runner than is maximal aerobic power. For runners with three or more previous marathons, training pace and body size are important. Maximal aerobic power, often considered the most important factor to marathon performance, is of lesser importance to the female marathoner.

\section{ACKNOWLEDGEMENTS}

The technical assistance of Cindy Dominguez, Mike Smith and Bill Kohl, as well as the participation of the subjects, is gratefully acknowledged.

\section{References}

Costill, D. L. and Fox, E. L., 1969 "Energetics of marathon running". Med.Sci. Sports 1: 81-86.

Costill, D. L. and Winrow, E., 1970 "Maximal oxygen intake among marathon runners". Arch.Phys.Med.Rehab. 51: 317-320.

Davies, C. T. M. and Thompson, M. W., 1979 "Aerobic performance of female marathon and male ultramarathon athletes". Eur.J.Appl.Physiol. 41: 233-245.

Doan, A. E., Peterson, D. R., Blackinson, J. R., Bruce, R. A., 1965 “Myocardial ischemia after maximal exercise in healthy men: a method for detecting potential coronary heart disease". Amer. Heart J. 69: 11, 12.

Farrell, P. A., Wilmore, J. H., Coyle, E. F., Billing, J. E. and Costill, D. L., 1979 "Plasma lactate accumulation and distance running performance". Med.Sci. Sports 11: 338-344.

Florey, C. DuV., 1970 "The use and interpretation of ponderal index and other weight-height ratios in epidemiological studies". J.Chron.Dis. 23: 93-103.

Foster, C., 1983 " $\mathrm{VO}_{2} \max$ and training indices as determinants or competitive running performance". J.Sports Sci. 1: 13-22.

Foster, C. and Daniels, J., 1975 "Running by the numbers". Runner's World 10: 14-17.

Foster, C., Daniels, J. T. and Yarbrough, R. A., 1977 "Physiological and training correlates of marathon running performance". Austral.J.Sports Med. 9: 58-61.

Franklin, B. A., Forgac, M. T. and Hellerstein, H. K., 1978 "Accuracy of predicted marathon time: relationship of training mileage to performance". Res.Quart. 49: 450-459.

Grant, S. J. Y., Sharp, R. H. and Aitchison, T. C., 1984 "First time marathoners and distance training". Brit.J.Sports Med. 18: 241-243.

Hagan, R. D., Smith, M. G. and Gettman, L. R., 1981 "Marathon performance in relation to maximal aerobic power and training indices". Med.Sci.Sports Ex. 13: 185-189.

Hagan, R. D., Strathman, T., Strathman, L. and Gettman, L. R., 1980 “Oxygen uptake and energy expenditure during horizontal treadmill running". J.Appl.Physiol. 49: 571-575. 
Jackson, A. S., Pollock, M. L. and Ward, A., 1980 "Generalized equations for predicting body density of women". Med.Sci.Sports Ex. 12: 175-182.

Jordan, D. B., 1977 "Analysis of exercise stress test responses of adult women marathon runners". J.Sports Med.Phys.Fit. 17: 59-64.

Maughan, R. J. and Leiper, J. B., 1983 "Aerobic capacity and fractional utilization of aerobic capacity in elite and non-elite male and female marathon runners". Eur.J.Appl.Physiol. 52: 80-87.

Pate, R. R. and Kriska, A., 1984 "Physiological basis of the sex difference in cardiorespiratory endurance". Sports Med. 1: 87-98.

Pugh, L. G. C. E., 1971 "The influence of wind resistance in running and walking and the mechanical efficiency of work against horizontal or vertical forces". J.Physiol.(London) 213: 255-276.
Siri, W. E., 1961 "Body composition from fluid spaces and density: analysis of methods." In: Techniques for Measuring Body Composition, Brozek, J. and Henschel, A. (Eds.). Wahington, D.C., National Academy of Sciences.

Sjödin, B. and Svedenhag, J., 1985 "Applied physiology of marathon running". Sports Med. 2: 83-99.

Slovic, P., 1977 "Empirical study of training and performance in the marathon". Res.Quart. 48: 769-777.

Wells, C. L., Hecht, L. H. and Krahenbuhl, G. S., 1981 "Physical characteristics and oxygen utilization of male and female marathon runners". Res.Quart. Ex.Sport 52: 281-285.

Wilmore, J. H. and Brown, C. H., 1974 "Physiological profiles of women distance runners". Med.Sci.Sports 6: 178-181.

Title:

\title{
BOOK REVIEW
}

Author:

\section{RUNNING RECOLLECTIONS AND HOW TO TRAIN}

Publisher:

\author{
A. R. Downer
}

Balgownie Books, Tarland, Aberdeenshire. 1982

Price: $£$ 3.95 150 pages ISBN 0946698007

An autobiography by A. R. Downer first published in 1902, has been published in facsimile by Balgownie Books. Downer, born in 1874, was a sprinter who won the 100, 220 and 440 yards Scottish AAA championships in three successive years (1883, 1884 and 1885). The book contains a fascinating account of illegal payments that were made more than 100 years ago for participation in particular events. In 1902 Downer wrote "How many so-called amateurs run for the pure love of the sport? Do not the most, in fact by far the most, enter and try to win only at those meetings where the best prizes are given ... I do not blame them - far from it - but I do condemn the smug hypocrisy of the governing body who recognise these things, and, knowing them to be contrary to their laws, make no attempt to prevent them ... " Athletics and its governing body does not seem to have changed much during 100 years.

Downer was suspended for ever from competing in amateur sports on 25th June, 1896. A fascinating account of professional races is described, from which one obtains some feeling of the intensity of the competitive spirit and the interesting use of handicaps in the sprint to ensure a race to the tape (or "the worsted" - as Downer describes it). I found the custom of the winner of a race giving five shillings to all the participants in the final, or as Downer described it "saving of a dollar all round", not only amusing but a commentary on the economics of the time - the exchange rate of four dollars to the pound must have been a stable rate for a considerable period of time for five shillings to be known as a "dollar" or $2 \mathrm{~s} 6 \mathrm{~d}$ as "half-a-dollar". Would we wish the British economy to be so strong at the present?

The book also contains information on the training regimens used by the various athletes in those early days. This is given by Downer, who was a sprinter, by E. C. Bredin a middle distance runner (half-mile champion of the world) and by Len Hurst a long distance runner, $(20$ mile champion of the world). The training regimens, in comparison to those of today, were, to say the least, light and walking was included in all the regimens. Interestingly, however all recommended training twice a day which is now becoming common practice, with some elite athletes now training four times per day. Most remarkable, however, were the diets eaten by these champions; meat appears to be the dominant food with stale bread and beer also recommended: "animal diet is alone prescribed and beef and mutton are preferred... the legs of the fowl are highly esteemed ... biscuits and stale bread are the only preparations of vegetable matter which are permitted..." This diet is totally unsuitable for athletes. Science can at least now suggest more sensible diets - but of course this does not mean that scientific.advice is taken by the athletes: my anecdotal information is that, for some current soccer players, boxers, tennis players and even track athletes, the normal diets may not be any better than those recommended in this book. Perhaps in the age of technology, many athletes are still in Downer's period of 'biscuits and stale bread'.

Eric Newsholme 